\title{
Hematologic abnormalities and associated factors among HIV infected children pre- and post- antiretroviral treatment, North West Ethiopia
}

This article was published in the following Dove Press journal:

Journal of Blood Medicine

4 August 2017

Number of times this article has been viewed

\section{Teshome Geletaw Meseret Zelalem Tadesse Abayneh Girma Demisse \\ Department of Pediatrics and Child Health, School of Medicine, College of Medicine and Health Science, University of Gondar, Ethiopia}

Introduction: There are few studies on the hematologic parameters of HIV-infected individuals in Ethiopia; of these, almost all studies researched adults. Our current study is unique in that it mainly focused on the pediatric population and compared both pre- and post-antiretroviral therapy (ART) children. Inference from this study can be used for other developing countries where the burden of HIV disease is high.

Objective: The aim of this study was to identify hematologic abnormalities in HIV-infected children before and after initiation of ART.

Methodology: A cross-sectional study was conducted on HIV-infected children from June 1 to August 30, 2015. Data were collected using a pretested and structured questionnaire. Statistical analysis was performed using SPSS 20 version.

Results: The median age of study subjects was 10 years with an interquartile range (IQR) of $(6,12)$. Two-thirds $(74.3 \%)$ of study subjects received ART for $>1$ year. The median of CD4 count before ART was 490 cells $/ \mathrm{mm}^{3}$ with an IQR of $(286,765)$; this increased to 663 cells $\mathrm{mm}^{3}$ with an IQR of $(499,908)$ after ART. Likewise, the median of hemoglobin before ART was $11.5 \mathrm{mg} /$ $\mathrm{dL}$ with an IQR of $(9.9,13)$, which increased after ART to $13 \mathrm{mg} / \mathrm{dL}$ with an IQR of $(11.8,14)$. The prevalence of anemia was $42.8 \%$ before and $18.9 \%$ after ART initiation. The median of absolute neutrophil count before ART was $3 \times 10^{3}$ with an IQR of $(2.1,4.6)$ and after ART, it became $3 \times 10^{3}$ with IQR of $(1.9,4.2)$. Age $<5$ years (adjusted odds ratio [AOR]: 2.76 ; 95\% CI: $1.5,5.0$ ), an advanced stage of AIDS (AOR: 2.8 ; 95\% CI: 1.4, 5.6) and CD4\% <25\% (AOR: $2.4 ; 95 \% \mathrm{CI}$ : $1.2,4.9)$ were significantly associated with anemia before ART initiation, while opportunistic infections were associated with anemia after initiation of ART (AOR: 2.3; 95\% CI: 1.08, 4.8).

Conclusion: ART positively or negatively affects the hematologic profile of HIV-infected children. The current study demonstrated a significant reduction of anemia after initiation of ART. Keywords: anemia, CD4 count, HIV, pediatrics, Gondar

\section{Introduction}

The annual rate of new HIV infections globally was believed to be 2.5 million in 2011. Approximately $12 \%$ of these infections (330,000 cases) occurred in children $<15$ years of age annually. ${ }^{1,2}$

In both antiretroviral-treated and untreated individuals, different types of hematological abnormalities were documented, the most important being pancytopenia. These changes are related with increased risk of morbidity and mortality. Anemia is a common finding in patients with HIV infection and it is more prevalent in patients with advanced retroviral infection. Its prevalence ranges from $11.7 \%$ to $92 \%$ depending on the stage of HIV disease, sex, age, pregnancy status, and presence of opportunistic
Demisse

School of Medicine, College of Medicine and Health Science, University of Gondar, Chechela Street, PO Box I I38, Gondar, Ethiopia

Tel +25l 9l 1367068

Email abaynehg@yahoo.com 
infections (OIs). As HIV disease progresses, the prevalence and severity of anemia also increases..$^{3-6}$ Thrombocytopenia is a frequent complication of HIV infection, which is found in $4 \%-40 \%$ of the cases and can occur at any stage of the infection. ${ }^{7}$ Leukopenia, specifically neutropenia, is the third most prevalent hematologic abnormality in HIV-infected individuals. It may occur in $2 \%-30 \%$ of HIV patients with advanced disease. ${ }^{8,9}$ Other causes include myelosuppressive drugs and OIs. Furthermore, HIV infection causes a decrease in cluster of differentiation 4 (CD4+) lymphocytes as the infection progresses. This can directly result in lymphopenia.,

Antiretroviral treatment (ART) is known to profoundly suppress viral replication. It increases CD4 cell count, delays disease progression and death; patients on highly active antiretroviral therapy commonly suffer from side effects of the drugs. ${ }^{10,11}$ Each antiretroviral (ARV) drug is associated with specific adverse effects. Among the ARV drugs, zidovudine (AZT) remains the most widely used drug, resulting in myelosuppression. ${ }^{12-14}$

There are few studies on the hematologic effects of HIV infection in Ethiopia but almost all were done on adult patients. Our current study is unique in that it focused on the pediatric population and compared both pre- and post-ART children.

\section{Methods and materials} Study design

A cross-sectional study was conducted from June 1 to August 30, 2015 on 222 HIV-infected children.

\section{Study area}

The study was done from June 1 to August 30, 2015 in University of Gondar Hospital. It is one of the tertiary hospitals in the country with catchment area of $\sim 7$ million people and the oldest academic institution in Ethiopia. The university is located at the heart of Gondar city, northwest part of the country. The HIV follow-up clinic is scheduled daily, both in the morning and afternoon. The clinic staffs 2 nurses and 3 doctors. The average patient census returning for follow-up was 15-20 patients per day. The hospital started delivering ART service in 2005; currently, there are 518 HIV-positive children enrolled in chronic follow-up care.

\section{Participants}

All HIV-infected children who had follow-up at pediatrics ART clinic in University of Gondar Hospital in the study period were included.

Reviews of patient charts were performed. The hematologic profile of patient was collected from the hospital's laboratory record book and anthropometry evaluation was done for each participant.

\section{Quantitative variables}

Measurement of height was performed by measuring in standing position. We used an electronic weight scale. Weight for age, weight for height and height for age were interpreted using the World Health Organization (WHO) growth curve.

\section{Inclusion criteria and exclusion criteria} Inclusion criteria

- All children $<15$ years of age who took ART for $>6$ months.

\section{Exclusion criteria}

- Patients who had traumatic injury or surgical interventions resulting in blood loss during the study period or within 3 months prior to the study period were excluded.

- Those children without a legal guardian or unaccompanied children.

\section{Sample size}

In order to have a representative sample of our entire pediatrics ART follow-up clinic, sample size was determined using single population proportion formula assuming the prevalence of anemia $53 \%,{ }^{25}$ with $5 \%$ margin of error and $95 \%$ CI. Since the source population was $<10,000$, correction formula was applied. Using the above assumption, the minimum sample size calculated was $220+22$ (10\% nonresponse rate) making the final sample size 240 . To select each study participants, we applied systematic random sampling technique, the 242 participants were selected from a sampling frame of 518 HIV-positive children who were on a follow-up care at the ART clinic. The interval $\mathrm{K}$ was 2 and every other participant from the sampling frame was included in the study.

\section{Data collection tools and procedure}

Data were collected using pre-tested structured questionnaires. These were composed of socio-demographic characteristics, and baseline characteristics of the study subjects before initiation of ART; these included mainly clinical, laboratory and immunological characteristics after initiation of ART.

Two nurses and 1 pediatrics resident were involved in the data collection. The laboratory measurements were done by experienced laboratory technologists. The data collection process was supervised strictly by the investigator. All study subjects were approached during their respective appointment 
schedule for follow-up and interviewed in a separate room to maintain confidentiality.

\section{Data compilation and analysis}

Data were reported as the mean and standard deviation for continuous variables and as percentages for categorical variables. Logistic regression analysis was applied to determine the associations of established risk factors for hematologic abnormalities. We used a CI of $95 \%$ and $P<0.05$ to evaluate for any significant association.

\section{Operational definitions}

Anemia, neutropenia and thrombocytopenia were defined based on WHO grading of hematologic toxicity. ${ }^{15}$ Accordingly, anemia was defined as hemoglobin ( $\mathrm{Hgb}$ ) concentration $\leq 10.5 \mathrm{~g} / \mathrm{dL}$ for all children and further severity was classified into grades as follows:

- Grade 1: Hemoglobin level of 8.5-10.5 g/dL (mild anemia)

- Grade 2: 7.5-<8.5 g/dL (moderate anemia)

- Grade 3: 6.5-<7.5 g/dL (severe anemia)

- Grade $4:<6.5 \mathrm{~g} / \mathrm{dL}$ (severe life-threatening anemia)

Thrombocytopenia: defined as platelet count $<150,000 / \mathrm{mm}^{3}$ Thrombocytosis: defined as platelet count $>450,000 / \mathrm{mm}^{3}$

Leukopenia: defined as white blood cell (WBC) count $<4000 / \mathrm{mm}^{3}$

Leucocytosis: defined as WBC count $>12,000 / \mathrm{mm}^{3}$ Lymphopenia: defined as lymphocyte count $<1500 / \mathrm{mm}^{3}$ Neutropenia: defined as absolute neutrophil count (ANC) of $<1500 / \mathrm{mm}^{3}$, severity further classified as follows:

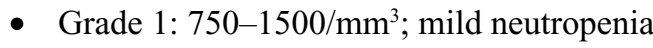

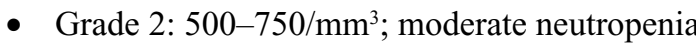

- Grade 3: $<500 / \mathrm{mm}^{3}$; severe neutropenia

- Grade 4: $<250 / \mathrm{mm}^{3}$; severe life-threatening neutropenia.

Weight for age $<5 \%$ was underweight and between 5 th $\%$ and 95 th $\%$ was normal. Height for age $<5 \%$ was stunted and between 5 th $\%$ and 95 th $\%$ was normal. ${ }^{16}$

Severe malnutrition was diagnosed if the child had either of the following: ${ }^{16}$

- Weight for height $(\mathrm{W} / \mathrm{H})<70 \%$

- Mid upper arm circumference $<11 \mathrm{~cm}$ (6 months-5 years), $<13 \mathrm{~cm}$ (5-10 years) and $<16 \mathrm{~cm}(11-16$ years)

- Weight for age (W/A) $<60 \%$ (marasmus) + edema $=$ kwashiorkor

\section{Ethical considerations}

We obtained ethical approval from the School of Medicine, University of Gondar research office before conducting the research. Study subjects were recruited after clear explanation of the study's objective. Written informed consent prepared in the local language (Amharic) was provided by the parents and additional verbal assent was taken for children between 10 and 14 years of age. All participants were informed of their right to withdraw from the study at any stage or to restrict their data from analysis; the interview took place in a separate room to ensure their privacy.

\section{Results \\ General characteristics of the study participants}

From a total of 242 randomly selected participants, 20 were excluded (12 because of incomplete documentations and 8 could not give consent) making the final study participants 222 . The median age of study subjects was 10 years with interquartile range (IQR) $(6,12)$. More than half, 120 (54.1\%), of the children were in early adolescent age. Female to male ratio was $1.12: 1$. Majority of the participants, 181 $(81.5 \%)$, resided in an urban area. Almost half, 109 (49.5\%), of the children had lost either/or both parents. One-third of the caregivers were illiterate $75(33.8 \%)$ and $36(16.2 \%)$ were college graduates (Table 1). The majority, 135 (61\%), of the study subjects were not disclosed their HIV status. The proportion of study participants who received AZT-based regimen was $176(79.28 \%)$, tenofovir (TDF)-based regimen was 26 (11.7\%), abacavir (ABC)-based regimen was 16 (7.2\%) and second-line drug was 4 (1.8\%) (Figure 1). Study subjects who received ART for $>12$ months were 165 (74.3).

\section{Clinical parameters}

We used WHO clinical staging system to grade severity of the diseases before ART, accordingly 85 (38.3\%) were stage 1 and 2, whereas $137(61.7 \%)$ participants were in clinical stage 3 and 4 .

Upon evaluation of nutritional status, 130 (58.6\%) and $139(62.6 \%)$ were found to be underweight and stunted, respectively before ART but after ART, the proportion of underweight and stunted children decreased significantly to $66(29.7 \%)$ and 74 (33.3\%), respectively. Severe malnutrition using WHO nutritional assessment criteria was identified in $14(31 \%)$ of the participants before ARV treatment and 2 $(0.9 \%)$ after ART. In the current study, pneumonia 65 (29.3\%) and tuberculosis $51(23 \%)$ were the top identified OIs before 
Table I Socio-demographic characteristics of HIV-infected children having follow-up in Gondar University Hospital, 2015

\begin{tabular}{ll}
\hline Variables & $\mathbf{n}(\%)$ \\
\hline Age (years) & $6(2.7)$ \\
$<1.5$ & $25(11.3)$ \\
$1.5-5$ & $71(32)$ \\
$5-10$ & $120(54.1)$ \\
$10-14$ & \\
Sex & $117(52.7)$ \\
Female & $105(47.3)$ \\
Male & \\
Residency & $181(81.5)$ \\
Urban & $41(18.5)$ \\
Rural & \\
Parent status & $112(50.5)$ \\
Both alive & $70(31.5)$ \\
Mother alive & $19(8.6)$ \\
Father alive & $21(9.5)$ \\
Both died & \\
Educational status of caregiver & $75(33.8)$ \\
Illiterate & $56(25.2)$ \\
Primary school & $55(24.8)$ \\
Secondary school & $36(16.2)$ \\
College/university & \\
Employment status of caregiver & $159(71.6)$ \\
Employed & $63(28.4)$ \\
Unemployed &
\end{tabular}

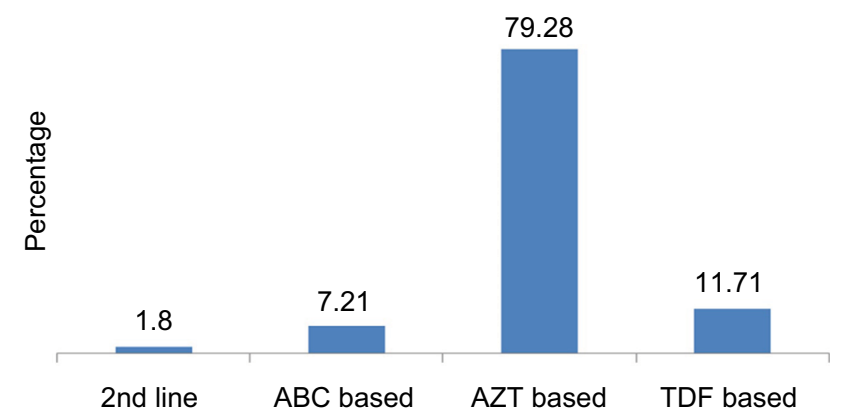

Figure I Percentage of antiretroviral drug used in children diagnosed with HIVI AIDS, University of Gondar, 2015.

Abbreviations: $A B C$, abacavir; $A Z T$, zidovudine; TDF, tenofovir.

ART. The overall prevalence of OIs was 148 (66.7\%) and 108 (48\%) before and after ART, respectively (Table 2 )

\section{Hematological and CD4 parameters}

The median Hgb before ART was $11.5 \mathrm{mg} / \mathrm{dL}$ with IQR of $(9.9,13)$, which increased after ART to $13 \mathrm{mg} / \mathrm{dL}$ with IQR of $(11.8,14)$.

The prevalence of anemia before initiation of ARV drugs was $42.8 \%$, whereas after ART, it decreased to $18.9 \%$ (Figure 2) and (Table 2). Of $18.9 \%$ of study subjects with anemia, $85.7 \%$ were taking AZT-based regimen, and 7.14\%
Table 2 Clinical and laboratory characteristics of HIV-infected children during follow-up in Gondar University Hospital, 2015

\begin{tabular}{|c|c|c|c|}
\hline Variable & $\begin{array}{l}\text { Before } \\
\text { ART n (\%) }\end{array}$ & $\begin{array}{l}\text { After } \\
\text { ART n (\%) }\end{array}$ & $P$-value \\
\hline \multicolumn{4}{|l|}{ Weight for age } \\
\hline$<5$ th percentile & $130(58.6)$ & $66(29.7)$ & \\
\hline$\geq 5$ th percentile & $92(41.4)$ & $156(70.3)$ & 0.000 \\
\hline \multicolumn{4}{|l|}{ Height for age } \\
\hline$<5$ th percentile & $139(62.6)$ & $74(33.3)$ & \\
\hline$\geq 5$ th percentile & $83(37.4)$ & $148(66.7)$ & 0.000 \\
\hline \multicolumn{4}{|l|}{ Weight for height, \% } \\
\hline$<70$ & $31(14)$ & $2(0.9)$ & \\
\hline 70-79 & $43(19.4)$ & $18(8.1)$ & \\
\hline $80-89$ & $7(3.2)$ & $23(10.4)$ & \\
\hline$\geq 90$ & I4I (63.5) & $179(80.6)$ & 0.000 \\
\hline \multicolumn{4}{|l|}{ Opportunistic infections } \\
\hline Tuberculosis & $35(15.7)$ & $12(5.4)$ & \\
\hline Persistent diarrhea & $23(10.4)$ & $19(8.5)$ & \\
\hline Pneumonia & $50(22.5)$ & $54(24.3)$ & \\
\hline *PCP & $49(1.8)$ & $4(1.8)$ & \\
\hline *Other opportunistic infections & $36(16.3)$ & $19(8.6)$ & \\
\hline No opportunistic infections & $74(33.3)$ & $114(5 \mid .4)$ & 0.000 \\
\hline \multicolumn{4}{|l|}{ Anemia } \\
\hline Yes & $95(42.8)$ & $42(18.9)$ & 0.000 \\
\hline \multicolumn{4}{|l|}{ Leukocytes } \\
\hline Leukopenia & $23(10.4)$ & $30(13.5)$ & \\
\hline Leukocytosis & $21(9.5)$ & $9(4.1)$ & \\
\hline Normal & I $78(80.2)$ & $183(82.4)$ & 0.230 \\
\hline \multicolumn{4}{|l|}{ Neutrophil count } \\
\hline Neutropenia & $23(10.4)$ & $35(15.8)$ & 0.310 \\
\hline \multicolumn{4}{|l|}{ Lymphocyte count } \\
\hline Lymphopenia & $33(14.9)$ & $21(9.5)$ & $0.05 \mathrm{I}$ \\
\hline \multicolumn{4}{|l|}{ Thrombocytes } \\
\hline Thrombocytopenia & $18(8.1)$ & $4(1.8)$ & \\
\hline Thrombocytosis & $40(18)$ & $31(14)$ & \\
\hline Normal & $164(73.9)$ & I $87(84.2)$ & 0.550 \\
\hline \multicolumn{4}{|l|}{ CD4 cell, \% } \\
\hline$<15$ & $52(23.4)$ & $18(8.1)$ & \\
\hline $15-25$ & $89(40.1)$ & $48(24.6)$ & \\
\hline$>25$ & $81(36.5)$ & $156(70.3)$ & 0.000 \\
\hline
\end{tabular}

Notes: ${ }^{\circ}$ Other $=$ Tuberculosis and pneumonia, otitis media and pyomyositis. Abbreviations: ART, antiretroviral treatment; PCP, Pneumocystis jirovecii pneumonia.

of them were on TDF-based regimen (Figure 3). Based on mean corpuscular volume, 66 (70\%) of patients had normocytic anemia before initiation of ART. Six (62\%) participants had macrocytic anemia after treatment with ARV drugs. The median of ANC before ART was $3 \times 10^{3}$ with IQR of (2.1, 4.6) and after ART, it became $3 \times 10^{3}$ with IQR of $(1.9,4.2)$.

When we looked at the CD4 count, the median of CD4 count before ART was 490 cells $/ \mathrm{mm}^{3}$ with IQR of $(286,765)$ and after ART, increased to 663 cells $/ \mathrm{mm}^{3}$ with IQR of (499, 908). According to WHO CD4 grading system, CD4\% $<15 \%$ before and after ARV treatment was $52(23.4 \%)$ and $18(8.1 \%)$, respectively and there was a significant improve- 


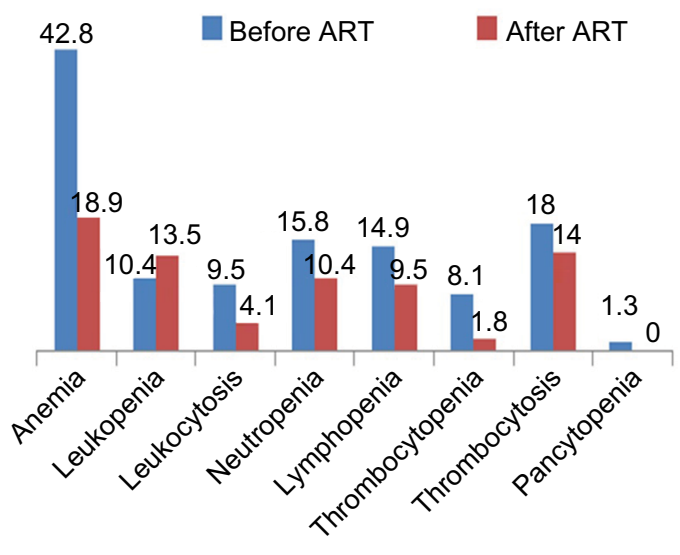

Figure 2 Hematologic profiles among HIV-infected children pre- and postantiretroviral treatment, University of Gondar Hospital, 2015. Abbreviation: ART, antiretroviral treatment.



Figure 3 Percentage of antiretroviral drugs among anemic children diagnosed to have HIV/AIDS, University of Gondar Hospital, 2015.

Abbreviations: $A B C$, abacavir; $A Z T$, zidovudine; TDF, tenofovir.

ment of (CD4\% > 25\%) among participants from 81 (36.5\%) pre-ART to $156(70.3 \%)$ after ART.

Using multivariate analysis; age $<5$ years (adjusted odds ratio [AOR]: 2.76; 95\% CI: 1.5, 5.0), advanced acquired immune deficiency syndrome (AIDS) stage (AOR: $2.8 ; 95 \%$ CI: $1.4,5.6$ ) and CD4\% <25\% (AOR: 2.4 ; 95\% CI: 1.2, 4.9) were significantly associated with anemia before ART initiation. The presence of OIs was independently associated with anemia after initiation of ARV treatment (AOR: $2.3 ; 95 \%$ CI: 1.08, 4.8). These factors were computed for other hematologic profiles; however, were not found to be statistically significant (Table 3 ).

\section{Discussion}

The current study investigated the occurrence of hematologic abnormalities among HIV-infected children. The most commonly identified were immune suppression, anemia and thrombocytopenia. The impact of HIV infection that can be found in the peripheral blood and bone marrow includes
Table 3 Factors associated with predictors of anemia among HIV-infected children before and after ART at Gondar University Hospital, 2015

\begin{tabular}{|c|c|c|c|c|}
\hline Variable & $\begin{array}{l}\text { Before } \\
\text { ART AOR }\end{array}$ & $P$-value & $\begin{array}{l}\text { After } \\
\text { ART AOR }\end{array}$ & $P$-value \\
\hline \multicolumn{5}{|l|}{ Age (years) } \\
\hline$\geq 5$ & I & & 1 & \\
\hline$<5$ & $2.76(1.5,5.0)$ & $0.001 *$ & $1.5(0.72,3.2)$ & 0.267 \\
\hline \multicolumn{5}{|l|}{ Sex } \\
\hline Male & I & & & \\
\hline Female & I.I5 $(0.6,2.0)$ & 0.6 & $0.75(0.3,1.5)$ & 0.432 \\
\hline \multicolumn{5}{|l|}{ Height for age } \\
\hline$>5$ th centile & I & & 1 & \\
\hline$<5$ th centile & I.4 $(0.7,2.8)$ & 0.32 & $0.8(0.3,1.8)$ & 0.669 \\
\hline \multicolumn{5}{|l|}{ Clinical staging } \\
\hline Early stage & 1 & & 1 & \\
\hline Advanced stage & $2.8(1.4,5.6)$ & $0.003 *$ & $2.1(0.8,5.7)$ & 0.119 \\
\hline \multicolumn{5}{|c|}{ Opportunistic infections } \\
\hline No & I & & 1 & \\
\hline Yes & I.78 $(0.8,3.6)$ & 0.103 & $2.3(1.08,4.8)$ & $0.03 *$ \\
\hline \multicolumn{5}{|l|}{ CD4, \% } \\
\hline$>25$ & I & & 1 & \\
\hline$<25$ & $2.4(1.2,4.9)$ & $0.001 *$ & $0.9(0.4,2.1)$ & $0.84 I$ \\
\hline
\end{tabular}

Notes: *P-value $<0.05$.

Abbreviations: AOR, adjusted odds ratio; ART, antiretroviral treatment.

anemia, leukopenia, thrombocytopenia and thrombocytosis. These could be because of direct effects of the virus on the bone marrow, suppression of bone marrow by secondary infections or neoplasm causing ineffective hematopoiesis; additionally, nutritional deficiencies or drug side effects are also potential contributors. ${ }^{17,18}$ The well-known mechanism of CD4+T cell depletion in HIV patients is related to apoptosis in which the dying cells exceed the number of HIV-infected cells. ${ }^{19,20}$ Before ART initiation, $63.5 \%$ of the patients had $\mathrm{CD} 4 \%<25 \%$ and among this group, $23.4 \%$ of patients had severe immunosuppression. But on the other hand, the prevalence of immunosuppression after ART declined to $30 \%$ and severe immunosuppression dropped to $8.1 \%$. In previous studies, after 12 months of ART, CD4 cell percentage data attained near-normal immune status. ${ }^{21}$

The prevalence of anemia before the initiation of ART in this study was $95(42.8 \%)$. This is similar to the studies done in Brazil, $37.5 \%,{ }^{22}$ and Uganda $47.8 \%{ }^{23}$ but lower than the Indian study $65.5 \%{ }^{24}$ These differences may be due to differences in study populations, socio-demographic characteristics of the study patients, sample size difference and diagnostic criteria used for anemia. The Ethiopian guideline published in 2007 recommends use of AZT-based regimen as a first line treatment but for those children with $\mathrm{Hgb}<8.5$ $\mathrm{gm} / \mathrm{dL}$, TDF- and ABC-based regimen was the preferred recommendation. ${ }^{25}$ Each ARV drug is associated with specific 
adverse effects, among the ARV drugs, AZT remains to be the most widely used drug, resulting in myelosuppression. ${ }^{12-14}$ In the current study among children who were diagnosed to have anemia after ART, $85.7 \%$ of them received AZT-based regimen. The prevalence of anemia declined significantly after ART with increment of Hgb by $1.3 \mathrm{gm} / \mathrm{dL}$. This is consistent with a study done in Jima, Ethiopia. ${ }^{26}$ Other studies also showed significant improvement in $\mathrm{Hgb}$ and related hematological indices while on ART, even without specific additional treatment. ${ }^{27}$

Thrombocytopenia was observed in $8.1 \%$ of the study patients, which is consistent with the study done in India, $7 \%,{ }^{24}$ in Uganda $8.3 \%,{ }^{23}$ and in Jima, Ethiopia, $7.8 \% .{ }^{26}$ Observation in other studies also identified thrombocytopenia in $10 \%-30 \%$ of $\mathrm{HIV}$-infected patients and increased incidence was found to be associated with the progression of HIV disease. ${ }^{28}$ Thrombocytopenia prevalence decreased to $1.8 \%$ after treatment with ARV drugs. This is similar to a study done in Jima. ${ }^{26}$ The mechanism of thrombocytopenia in HIV infection is mainly due to ineffective platelet production and increased platelet destruction by the spleen.

In the current study, young age ( $<5$ years), advanced stage and immunosuppression were independently associated with anemia which is consistent with other published studies. ${ }^{29}$ Published literature on this area indicates that disease progression and severe immunosuppression are associated with cytokine-mediated myelosuppression resulting in multiple hematologic abnormalities, including anemia. ${ }^{30}$

OIs are reported to attack the bone marrow in patients with HIV. These infections may cause marrow changes either directly by the organism itself or indirectly by causing reactive changes. ${ }^{31}$

\section{Limitations}

The current study has to be interpreted with few limitations. We did not identify the exact cause of anemia though its prevalence was high prior to ART.

\section{Conclusion}

We conclude that anemia was the top abnormality identified, followed by thrombocytopenia and leukopenia. After ART initiation, there was a significant improvement of the hematologic profile in the current study.

\section{Acknowledgments}

We want to acknowledge University of Gondar and our colleagues who directly or indirectly helped us to finish this study. Our acknowledgment also extends to Dr Michelle
Yates, Dr Nebiyu Mesfin, Dr Solomon Mekonnen and Dr Wubishet Lakew for editing the manuscript.

\section{Author contributions}

All authors contributed toward data analysis, drafting and revising the paper and agree to be accountable for all aspects of the work.

\section{Disclosure}

The authors report no conflicts of interest in this work.

\section{References}

1. UNAIDS: On the global AIDS epidemic 2012 Report. Available from: http://www.refworld.org/docid/50eebaf52.html. Accessed April 24, 2017.

2. Federal Democratic Republic of Ethiopia Ministry of Health Sector Development Program IV 2010/11 - 2014/15. FMOH, October 2010. Available from: http://www.nationalplanningcycles.org/sites/default/ files/country_docs/Ethiopia/ethiopia_hsdp_iv_final_draft_2010_-2015. pdf. Accessed April 15, 2017.

3. Sudhir M, Srinivasa J, Dinesh Gautam. Hematologic Manifestations of HIV/AIDS. Med Update. 2011; $484-\mathrm{e} 488$.

4. Kreuzer KA, Rockstroh JK. Pathogenesis and pathophysiology of anemia in HIV infection. Ann Hematol. 1997;75(5-6):179-187.

5. Torsak B, Azar K, Kwai C, et al. Incidence and predictors of severe anemia in Asian HIV-infected children using first-line antiretroviral therapy. Int J Infect Dis. 2013;17:e806-e810.

6. Kosalaraksa P, Bunupuradah T, Vonthanak S, et al. Prevalence of anemia and underlying iron status in naive antiretroviral therapy HIV-infected children with moderate immune suppression. AIDS Res Hum Retroviruses. 2012;28(12):1679-1686.

7. Liebman HA. Viral-associated immune thrombocytopenic purpura. Hematology Am Soc Hematol Educ Program. 2008;1:212-218.

8. Kyeyune R, Saathoff E, Ezeamama A, Löscher T, Fawzi W, Guwatudde D. Prevalence and correlates of cytopenias in HIV-infected adults initiating highly active antiretroviral therapy in Uganda. BMC Infect Dis. 2014; 14:496.

9. Akinbami A, Oshinaike O, Adeyemo T, Adediran A, Dosunmu O. Hematologic abnormalities in treatment-naïve HIV patients. Lagos, Nigeria. Infect Dis Res Treatment. 2010;3:45-49.

10. Ira S, Bhushan K. Hematological manifestations in HAART naïve HIV-1 infected children in India in a resource limited setting. Pediatric Call J. 2011;8:5.

11. Denue BA, Gashau W, Bello HS, Kida I, Bakki B, Ajayi B. Relation between some hematological abnormalities, degree of immunosuppression and viral load in treatment-naïve HIV-infected patients Eastern Nigeria. East Mediterr Health J. 2013;19(5):362-368.

12. De Jesus E, Herrera G, Teofilo E, et al. Abacavir versus zidovudine combined with lamivudine and efavirenz, for the treatment of antiretroviralnaive HIV-infected adults. Clin Infect Dis. 2004;39(7):1038-1046.

13. Lorna A, Fatoumata D, Fla K, et al. Anemia and zidovudine-containing antiretroviral therapy in pediatric antiretroviral programs in the IeDEA pediatric West African database to evaluate AIDS. J Int AIDS Soc. 2013;16(1):18024.

14. Moyle G, Sawyer W, Law M, Amin J, Hill A. Changes in the efficacy of thymidine analog-based HAART: a meta-analysis of six prospective, randomized, comparative studies. Clin Ther. 2004;26:1.

15. Aldeman H, Shekar M. Nutrition and health. In: Richard E. Behrman, editors. Nelson Text Book of Pediatrics. California: Elsevier; 2015:297-299.

16. Firnhaber C, Smeaton L, Saukila N, et al. Comparisons of anemia, thrombocytopenia, and neutropenia at initiation of HIV antiretroviral therapy in Africa, Asia, and the Americas. Int $J$ Infect Dis. 2010;14(12):e1 088-e1092. 
17. Zon LI, Groopman JE. Hematologic manifestations of the human immunodeficiency virus (HIV). Semin Hematol 1988;25:208-218.

18. Basu A, Ghosh K, Banerjee K. Bone marrow involvement in HIV infection: light, electron and immuno electron microscopic studies. Indian J Hematol Blood Transf. 1999;17(4)76-86.

19. Holm GH, Zhang C, Gorry PR, et al. Apoptosis of bystander T cells induced by human immunodeficiency virus type 1 with increased envelope/receptor affinity and coreceptor binding site exposure. JVirol. 2004;78:4541-4551.

20. Fevrier M, Dorgham K, Rebollo A. CD4+T cell depletion in human immunodeficiency virus (HIV) infection: role of apoptosis. Viruses. 2011;3(5):586-612.

21. Zheng J, Zhao D. Clinical, immunological, and virological outcomes of pediatric antiretroviral therapy in central China. BMC Res Notes. 2014;7:419.

22. De Santis GC, Brunetta DM, Vilar FC, et al. Hematological abnormalities in HIV-infected patients in University of Sa o Paulo, Brazil. Int $J$ Infect Dis. 2011;15:e808-e811.

23. Eunice N, Francis B, Julius K. Anemia in HIV-infected children: severity, types and effect on response to HAART in Rural Uganda. BMC Pediatr. 2012;12:170.

24. Dikshit B, Wanchu A, Sachdeva K, Sharma A, Das R. Profile of hematological abnormalities of Indian HIV infected individuals. BMC Blood Disord. 2009;9:5.
25. Federal Democratic Republic of Ethiopia Ministry of Health. Federal HIV/AIDS Prevention and Control Office. Guidelines for Pediatric HIV/ AIDS Care and Treatment in Ethiopia. July 2007. Available from: http:// www.ilo.org/wcmsp5/groups/public/---ed_protect/---protrav/---ilo_aids/ documents/legaldocument/wcms_125387.pdf. Accessed June 15, 2017.

26. Muluneh A, Fessahaye A. Hematologic abnormalities among children on HAART in Jimma University Specialized Hospital. Ethiop J Health Sci. 2009;19(2):83-89.

27. Musoke PM, Mudiope P, Barlow-Mosha LN, et al. Growth, immune and viral responses in HIV infected African children receiving highly active antiretroviral therapy: a prospective cohort study. BMC Pediatr. 2010;10:56.

28. Vannappagari V, Nkhoma ET, Atashili J, Laurent SS, Zhao H. Prevalence, severity, and duration of thrombocytopenia among HIV patients; in the era of highly active antiretroviral therapy. Platelets. 2011;22(8):611-618.

29. Nyesigire Ruhinda E, Bajunirwe F, Kiwanuka J. Anemia in HIV-infected children: severity, types and effect on response to HAART. BMC Pediatrics. 2012;12:170.

30. Shet A, Bhavani P, Kumarasamy N, et al. Anemia, diet and therapeutic iron among children living with HIV: a prospective cohort study. $B M C$ Pediatrics. 2015;15:164

31. Tripathi AK, Misra R, Kalra P, Gupta N, Ahmad R. Bone marrow abnormalities in HIV disease. J Assoc Physicians India. 2005;53:705-710.
Journal of Blood Medicine

\section{Publish your work in this journal}

The Journal of Blood Medicine is an international, peer-reviewed, open access, online journal publishing laboratory, experimental and clinical aspects of all aspect pertaining to blood based medicine including but not limited to: Transfusion Medicine; Blood collection, Donor issues, Transmittable diseases, and Blood banking logistics; Immunohematology; Artificial and alternative

\section{Dovepress}

blood based therapeutics; Hematology; Biotechnology/nanotechnology of blood related medicine; Legal aspects of blood medicine; Historical perspectives. The manuscript management system is completely online and includes a very quick and fair peer-review system. Visit http://www.dovepress.com/ testimonials.php to read real quotes from published authors. 